\title{
ANÁLISE DA ABORDAGEM AMBIENTAL NO COMPONENTE CURRICULAR QUÍMICA
}

Apresentação: Pôster

\author{
Isla Marcolino da Silva ${ }^{1}$; Keliana Dantas Santos ${ }^{2}$
}

\section{Introdução}

A partir da década de 1970 há uma preocupação em nível global com a importância da preservação e conservação ambiental, buscando práticas educativas que sensibilizem os discentes a fim de fomentar um novo pensamento a respeito da natureza e estreitar seus laços com o ser humano. Sendo necessário traçar um caminho para a construção de sociedades mais sustentáveis e fomentar a consciência coletiva a fim de promover uma utilização dos recursos naturais considerando a equidade e durabilidade.

A Educação Ambiental emerge como tentativa de sensibilizar sobre questões possibilitando à população uma maneira de formar uma opinião mais crítica e capaz de mudar suas atitudes no que diz respeito ao assunto.

O Conselho Nacional do Meio Ambiente (CONAMA) traz a definição de que a Educação Ambiental é processo de formação e informação orientada para o desenvolvimento da consciência crítica sobre as questões ambientais e de atividades que levem à participação das comunidades na preservação do equilíbrio ambiental. De acordo com o (PCN, 2000), relacionar o meio ambiente e seus problemas com o ensino de Química possibilita "a compreensão tanto dos processos químicos em si quanto da construção de um conhecimento científico em estreita relação com as aplicações tecnológicas e suas implicações ambientais...”.

Desse modo, os educadores devem tomar uma postura protagonista no sentido de contextualizar o ensino de ciências, não apenas descrever os fenômenos naturais cientificamente, como também explorar as dimensões sociais e culturais nas quais os discentes estão inseridos. Pois possuem um papel inestimável, por se tratar de facilitadores de conhecimento, estruturam sua prática educativa a fim de difundir o conhecimento, respeitando e ampliando o conhecimento prévio e as experiências dos discentes.

\footnotetext{
${ }^{1}$ Licenciatura em Química, IFPB, isla.marcolino@gmail.com

${ }^{2}$ Professora Doutora em Química, IFPB, keliana.santos@ifpb.edu.br
} 
Os planos de ensino são instrumentos básicos no trabalho dos educadores, pois devem conter todo o seu processo educacional e as propostas de trabalho que serão executadas. $\mathrm{O}$ planejamento, dentre o contexto educativo, busca uma forma de ensino-aprendizagem democrática e transformadora. Para Vasconcellos (1971), os planos de ensino correspondem ao maior nível de detalhamento e objetividade no processo de planejamento didático. Logo, é de fundamental importância analisar criticamente e perceber o perfil de cidadão ou de profissional que a instituição de ensino quer formar, se seus objetivos são educacionais ou meramente conteudistas.

Portanto, este estudo tem como objetivo analisar a forma em que a química ambiental é abordada nos planos de ensino do componente curricular química do Curso Técnico Integrado de Controle Ambiental do Instituto Federal de Educação, Ciência e Tecnologia da Paraíba - Campus João Pessoa.

\section{Fundamentação Teórica}

A Lei de Diretrizes e Bases da Educação em seu artigo $1, \S 2^{\circ}$ diz que a educação escolar deverá vincular-se ao mundo do trabalho e à prática social. Pode-se dizer assim, que a ideia de incentivo as práticas educativas mais dinâmicas e mutáveis, podem ser construída juntamente com a contextualização entre disciplinas estudadas e a sua relação com o cotidiano, de forma clara que visem unir: educação, conscientização ambiental e a prática social.

Remetemo-nos à alfabetização científica, que é considerada como uma alternativa numa linha que surge da didática no ensino de ciências, que por meio de uma linguagem cientifica reconhece em acontecimentos cotidianos conceitos que ali existem. Ou seja, o ensino de ciências integra a lógica, a escrita e a leitura, fazendo com o que os discentes compreendam os conceitos científicos, chegando ao abstrato a partir do concreto, estabelecendo uma ligação com o senso comum. Como na seguinte consideração de Chassot (2007): "não se pode mais conceber propostas para um ensino de ciências, sem incluir nos currículos componentes que estejam orientados na busca de aspectos sociais".

Uma vertente da Química é a Química Ambiental que estuda todos os processos químicos que ocorrem na natureza seja de forma natural ou antropicamente. Busca desenvolver medidas que possam beneficiar o meio ambiente, consequentemente, favorecer a nossa sociedade com uma melhor qualidade de vida e também para seguirmos um caminho cada vez mais sustentável, visto que está intimamente presente em tudo ao nosso redor. Para Santos \& Schnetzler (2003): 
bem como se posicionarem criticamente com relação aos efeitos ambientais da utilização da química e quanto as decisões referentes aos investimentos nessa área, a fim de buscar soluções para os problemas sociais que podem ser resolvidos com a ajuda do seu desenvolvimento".

\section{Metodologia}

A presente pesquisa trata-se de uma análise de conteúdo buscando analisar a abordagem ambiental dos planos de ensino da componente curricular química das turmas de $1^{\circ}, 2^{\circ}$ e $3^{\circ}$ ano, do Curso Técnico Integrado de Controle Ambiental do Instituto Federal de Educação, Ciência e Tecnologia da Paraíba, Campus João Pessoa. Seguindo como referencial teórico Bardin (2011), constituído pelas etapas de "pré-ánalise, inferência e interpretação". Primeiramente, foram determinadas duas categorias e seus respectivos indicadores.

\section{Categorias de Análise}

Interdisciplinaridade e Aspectos Ambientais - Indicadores: Propõe integração entre duas ou mais disciplinas para abordagem ambiental?

Articulam questões sociais, políticas e éticas relacionadas a questões ambientais?

Proposição de Atividades - Indicadores: Sugere atividades que relacionem educação ambiental com o cotidiano do aluno? Sugere atividades que propicie a discussão de problemas ambientais e seus impactos?

\section{Resultados e Discussões}

As análises e discussões referem-se à adequação dos planos de ensino de química do Ensino Médio quanto às perspectivas de uma educação contemporânea e consciente quanto ao meio ambiente e voltada para o exercício da cidadania e práticas sustentáveis. A seguir serão apresentadas, de forma sintética, as análises dos planos de ensino selecionados. É importante ressaltar os planos de ensino que obtiveram a sigla AT, apresentaram dados que se adequam totalmente ao indicador em questão, de forma clara; no que tange a sigla AP, remete-se a citação de informações, mas não a descreve; enquanto NA significa que o plano em questão não fornece as informações necessárias para o indicador.

\section{Análise do Plano de Ensino do $1^{\circ}$ ano:}

\begin{tabular}{|c|c|c|c|}
\hline $\begin{array}{c}\text { Propõe integração } \\
\text { entre dois ou mais } \\
\text { componentes }\end{array}$ & $\begin{array}{c}\text { Articulam questões } \\
\text { sociais, políticas e } \\
\text { éticas relacionadas a }\end{array}$ & $\begin{array}{c}\text { Sugere atividades que } \\
\text { relacionem educação } \\
\text { ambiental com o }\end{array}$ & $\begin{array}{c}\text { Sugere atividades que } \\
\text { propiciem a discussão } \\
\text { de problemas }\end{array}$ \\
\hline
\end{tabular}




\begin{tabular}{|c|c|c|c|}
\hline $\begin{array}{c}\text { curriculares para } \\
\text { abordagem ambiental? }\end{array}$ & questões ambientais? & cotidiano do aluno? & $\begin{array}{c}\text { ambientais e seus } \\
\text { impactos? }\end{array}$ \\
\hline AP & AP & AP & NA \\
\hline
\end{tabular}

Legendas: $\mathrm{AT}=$ Atende Totalmente, $\mathrm{AP}=$ Atende Parcialmente, $\mathrm{NA}=$ Não Atende.

\section{Análise do Plano de Ensino do $2^{\circ}$ ano:}

\begin{tabular}{|c|c|c|c|}
\hline $\begin{array}{c}\text { Propõe integração } \\
\text { entre dois ou mais } \\
\text { componentes } \\
\text { curriculares para } \\
\text { abordagem ambiental? }\end{array}$ & $\begin{array}{c}\text { Articulam questões } \\
\text { sociais, políticas e } \\
\text { éticas relacionadas a } \\
\text { questões ambientais? }\end{array}$ & $\begin{array}{c}\text { Sugere atividades que } \\
\text { relacionem educação } \\
\text { ambiental com o } \\
\text { cotidiano do aluno? }\end{array}$ & $\begin{array}{c}\text { Sugere atividades que } \\
\text { propicie a discussão de } \\
\text { problemas ambientais } \\
\text { e seus impactos? }\end{array}$ \\
\hline AP & NA & NA & NA \\
\hline
\end{tabular}

Análise do Plano de Ensino do $3^{\circ}$ ano:

\begin{tabular}{|c|c|c|c|}
\hline $\begin{array}{c}\text { Propõe integração } \\
\text { entre dois ou mais } \\
\text { componentes } \\
\text { curriculares para } \\
\text { abordagem ambiental? }\end{array}$ & $\begin{array}{c}\text { Articulam questões } \\
\text { sociais, políticas e } \\
\text { éticas relacionadas a } \\
\text { questões ambientais? }\end{array}$ & $\begin{array}{c}\text { Sugere atividades que } \\
\text { relacionem educação } \\
\text { ambiental com o } \\
\text { cotidiano do aluno? }\end{array}$ & $\begin{array}{c}\text { Sugere atividades que } \\
\text { propicie a discussão de } \\
\text { problemas ambientais } \\
\text { e seus impactos? }\end{array}$ \\
\hline AT & AT & AP & NA \\
\hline
\end{tabular}

De forma geral, a análise dos planos de ensino na categoria Interdisciplinaridade e Aspectos Ambientais - Indicador "Propõe integração entre dois ou mais componentes curriculares para abordagem ambiental?", se apresentaram como satisfatório, visto que todos atendem parcialmente a totalmente as questões e sugerem um projeto interdisciplinar durante a componente curricular de química. No tocante, a articulações de questões sociais, políticas e éticas relacionadas a questões ambientais, os planos de ensino apresentam resultados distintos. Nos planos de ensino tanto do $1^{\circ}$ ano quanto do $3^{\circ}$ ano, atendem parcialmente e totalmente, uma vez que em sua ementa propõe que "têm-se a visão do que a natureza oferece ao homem, os recursos naturais e com a evolução do desenvolvimento tecnológico surgiu os recursos sintéticos e emergiu o desequilíbrio ambiental" e ressalta a necessidade de que discentes tenham conhecimento da evolução histórica da química. No entanto, o plano de ensino do $2^{\circ}$ ano não atende a este quesito, em nenhum ponto sugere ou cita tais incentivos. Quanto à categoria de Proposição de atividades, os planos de ensino tanto do $1^{\circ}$ ano 
quanto do $3^{\circ}$ ano atendem parcialmente, trazendo como objetivos específicos "identificar a presença da química na vida cotidiana" e "identificar no cotidiano as diversas utilizações de substâncias orgânicas", respectivamente. A proposta está presente nos planos, porém não existe uma descrição mais elaborada.

Diferente do plano de ensino do $2^{\circ}$ ano, que nesse sentido é meramente conteudista. O que é preocupante, visto que as atividades auxiliam na compreensão dos conhecimentos específicos da componente curricular, promove o debate e respeito às opiniões. Quanto à sugestão de atividades que propicie a discussão de problemas ambientais e seus impactos, todos os planos apresentam o mesmo resultado, nenhum atendeu ao questionamento, simplesmente não são trazidas para discussão mesmo com a grande importância da proposta e do tema.

\section{Conclusões}

Com base na análise realizada nos planos de ensino do componente curricular química para o ensino médio, utilizado pelo Instituto Federal de Educação, Ciência e Tecnologia da Paraíba no curso de Controle Ambiental, observamos que existe certa preocupação por parte dos autores em inserir a química ambiental em seu plano didático, porém os planos não apresentam uma abordagem completa em um determinado assunto. Citam a educação ambiental ou sugerem atividades muito resumidamente, o foco principal são os conteúdos. Os planos diferem entre si, porém o foco de preocupação é mais centrado nos conteúdos que os discentes necessitam para determinada série, já esperado visto que todos os planos foram escritos pelos mesmos autores e autora. Outro fato que chama atenção é a reprodução do plano de ensino durante anos, analisamos a última atualização, que ocorreu em 2012.

\section{Referências}

BARDIN, L. Análise de Conteúdo. Editora: Edições 70, 2011.

BRASIL. Parâmetros Curriculares Nacionais (PCN) - Ensino Médio; Ministério da Educação, 2000.

BRASIL. Lei $\mathbf{n}^{0}$ 9.394, de 20 de dezembro de 1996. Diretrizes e Bases da Educação Nacional. Brasília, DF, 1996. P. 1-31.

CHASSOT, A. Educação ConSciência. Segunda Edição. Santa Cruz do Sul: EDUNISC, 2007.

SANTOS, W. L. P., \& SCHNETZLER, R. P. Educação em Química: compromisso com a cidadania. Terceira Edição. Ijuí: Unijuí, 2003.

VASCONCELOS, C. S. Planejamento: projeto de ensino-aprendizagem e projeto políticopedagógico. Décima Edição. Cadernos Pedagógicos do Libertad, volume1. São Paulo: Libertad, 2002. 